\title{
Cardiac avoidance in breast radiotherapy: many choices for a worthwhile objective
}

\author{
Atif J. Khan ${ }^{1}{ }^{*}$, Sharad Goyal ${ }^{1}$ and Frank A. Vicini ${ }^{2}$ \\ ${ }^{1}$ Rutgers Cancer Institute of New Jersey, Robert Wood Johnson University Hospital, New Brunswick, NJ, USA \\ ${ }^{2}$ Michigan Healthcare Professionals, Farmington Hills, MI, USA \\ *Correspondence: khanat@cinj.rutgers.edu
}

Edited by:

John Varlotto, University of Massachusetts Medical Center, USA

Reviewed by:

Alina Mihaela Mihai, UPMC Beacon Hospital, Ireland

Charles B. Simone, University of Pennsylvania, USA

Keywords: prone breast, deep inspiration breath hold, accelerated partial breast irradiation, proton therapy, cardiac avoidance

In this Research Topic, Goyal and Haffty have collected a series of papers on the emerging field of cardio-oncology. Indeed, Darby et al.'s paper demonstrating an incremental 7\% increase in risk of ischemic events per gray increase in mean heart dose has been a watershed moment in our efforts to improve the therapeutic ratio of adjuvant breast radiotherapy (1). While a 0.07 increase over baseline risk per Sievert may seem high, it is important to understand this relative increase in risk in the context of the absolute baseline risk. Darby and colleagues do not provide a denominator for eligible patients in the two population registries from which they drew their cases and controls. Instead, they estimate the baseline risk using data from 15 Western European nations, and in Table S12 of the Supplementary Material, go on to estimate the absolute risk increase by age 80 years in women exposed to RT at various ages and with various co-morbid risk profiles. The excess absolute risks appear to be modest at first glance. For example, for a young 40 -year-old woman receiving a high mean heart dose of $10 \mathrm{~Gy}$, the estimated absolute excess risk of dying from cardiac disease is about $1.4 \%$. Should the same woman have at least one co-morbid risk factor, her excess risk is $2.3 \%$. These numbers may seem small, but are certainly relevant at the population level, especially given that the mortality benefit of adjuvant radiotherapy is also modest (2). Current efforts at reducing the risks of incidental cardiac irradiation have included advanced radiotherapy techniques for cardiac avoidance such as breath hold (3), gating treatments (4), proton therapy (5), prone positioning (6), and combinations thereof such as respiratory gating in the prone position (7).

Cardiac avoidance techniques are illustrative of the general potential that technological innovations can have on human health. Going back to the very development of megavoltage machines, improvements in radiation delivery have consistently improved the therapeutic ratio in any number of settings. Recent reports have demonstrated fewer late second malignancies in children treated with proton therapy (8), lower rates of desquamation in breast cancer patients treated with IMRT (9), higher rates of local control in lung cancer patients treated with SBRT (10), and improved biochemical control in patients treated with highly conformal, high-dose radiotherapy for prostate cancer (11). Similar improvements in image-guided gynecological brachytherapy (12), IMRT in head/neck (13), GI (14), and gynecological malignancies (15), as well as intracranial SRS (16) have all demonstrated better outcomes compared with control data. Even as the calls for controlling costs become ever more constant, it is important to remember that the current excitement for a genomically driven model of cancer care has become possible only because of technological improvements in sequencing technologies. As such, continued funding, both federal and private, for technology innovations is critical and should not be relegated to lower tiers of priority.

Coming back to breast cancer patients and the cardiac risks they face from radiotherapy, one additional (seemingly obvious) point needs to be made. While we can invoke continually advancing technologies for the purposes of cardiac avoidance (17), sometimes a return to simpler solutions may be all that is needed. Many women with early-stage breast cancer are eligible for off-protocol accelerated partial breast irradiation as a standard of care option (18). As one would expect, irradiating a smaller volume of breast tissue leads to lower incidental heart doses (19). Current studies and protocols examining, for example, breath hold parameters or prone positioning often include a large contingent of women who are candidates for partial breast irradiation. One rather elegant way to avoid treating the heart is to simply not treat it.

\section{REFERENCES}

1. Darby SC, Ewertz M, McGale P, Bennet AM, BlomGoldman U, Brønnum D, et al. Risk of ischemic heart disease in women after radiotherapy for breast cancer. NEngl JMed (2013) 368(11):987-98. doi:10.1056/NEJMoa1209825

2. Early Breast Cancer Trialists' Collaborative G, Darby S, McGale P, Correa C, Taylor C, Arriagada $\mathrm{R}$, et al. Effect of radiotherapy after breastconserving surgery on 10-year recurrence and 15year breast cancer death: meta-analysis of individual patient data for 10,801 women in 17 randomised trials. Lancet (2011) 378(9804):1707-16. doi:10.1016/S0140-6736(11)61629-2

3. Zellars R, Bravo PE, Tryggestad E, Hopfer K, Myers L, Tahari A, et al. SPECT analysis of cardiac perfusion changes after whole-breast/chest wall radiation therapy with or without active breathing coordinator: results of a randomized phase 3 trial. Int J Radiat Oncol Biol Phys (2014) 88(4):778-85. doi:10.1016/j.ijrobp.2013.12.035

4. Giraud P, Djadi-Prat J, Morelle M, Pourel N, Durdux C, Carrie C, et al. Contribution of respiratory gating techniques for optimization of breast cancer radiotherapy. Cancer Investig (2012) 30(4):323-30. doi:10.3109/07357907.2012.657818

5. MacDonald SM, Patel SA, Hickey S, et al. Proton therapy for breast cancer after mastectomy: 
early outcomes of a prospective clinical trial. Int J Radiat Oncol Biol Phys (2013) 86(3):484-90. doi:10.1016/j.ijrobp.2013.01.038

6. Raza S, Lymberis SC, Ciervide R, Axelrod D, Fenton-Kerimian M, Magnolfi C, et al. Comparison of acute and late toxicity of two regimens of 3- and 5-week concomitant boost prone IMRT to standard 6-week breast radiotherapy. Front Oncol (2012) 2:44. doi:10.3389/fonc.2012.00044

7. Mulliez T, Speleers B, Mahjoubi K, Remouchamps V, Gilsoul M, Veldeman L, et al. Prone leftsided whole-breast irradiation: significant heart dose reduction using end-inspiratory versus endexpiratory gating. Cancer Radiother (2014). doi:10. 1016/j.canrad.2014.04.004

8. Chung CS, Yock TI, Nelson K, Xu Y, Keating NL, Tarbell NJ. Incidence of second malignancies among patients treated with proton versus photon radiation. Int J Radiat Oncol Biol Phys (2013) 87(1):46-52. doi:10.1016/j.ijrobp.2013.04. 030

9. Pignol JP, Olivotto I, Rakovitch E, Gardner S, Sixel $\mathrm{K}$, Beckham $\mathrm{W}$, et al. A multicenter randomized trial of breast intensity-modulated radiation therapy to reduce acute radiation dermatitis. J Clin Oncol (2008) 26(13):2085-92. doi:10.1200/JCO. 2007.15.2488

10. Iyengar P, Westover K, Timmerman RD. Stereotactic ablative radiotherapy (SABR) for non-small cell lung cancer. Semin Respir Crit Care Med (2013) 34(6):845-54. doi:10.1055/s-0033-1358554

11. Spratt DE, Zumsteg ZS, Ghadjar P, Kollmeier MA, Pei X, Cohen G, et al. Comparison of high-dose (86.4 Gy) IMRT vs combined brachytherapy plus IMRT for intermediate-risk prostate cancer. BJU Int (2013). doi:10.1111/bju.12514
12. Pötter R, Dimopoulos J, Georg P, Lang S, Waldhäusl C, Wachter-Gerstner $\mathrm{N}$, et al. Clinical impact of MRI assisted dose volume adaptation and dose escalation in brachytherapy of locally advanced cervix cancer. Radiother Oncol (2007) 83(2):148-55. doi:10.1016/j.radonc.2007. 04.012

13. Lee N, Harris J, Garden AS, et al. Intensitymodulated radiation therapy with or without chemotherapy for nasopharyngeal carcinoma: radiation therapy oncology group phase II trial 0225. J Clin Oncol (2009) 27(22):3684-90. doi:10. 1200/JCO.2008.19.9109

14. Salama JK, Mell LK, Schomas DA, et al. Concurrent chemotherapy and intensity-modulated radiation therapy for anal canal cancer patients: a multicenter experience. J Clin Oncol (2007) 25(29):4581-6. doi:10.1200/JCO.2007.12.0170

15. Hasselle MD, Rose BS, Kochanski JD, Nath SK, Bafana R, Yashar CM, et al. Clinical outcomes of intensity-modulated pelvic radiation therapy for carcinoma of the cervix. Int J Radiat Oncol Biol Phys (2011) 80(5):1436-45. doi:10.1016/j.ijrobp. 2010.04.041

16. Andrews DW, Scott CB, Sperduto PW, et al. Whole brain radiation therapy with or without stereotactic radiosurgery boost for patients with one to three brain metastases: phase III results of the RTOG 9508 randomised trial. Lancet (2004) 363(9422):1665-72. doi:10.1016/S0140-6736(04) 16250-8

17. Shah C, Badiyan S, Berry S, Khan AJ, Goyal $\mathrm{S}$, Schulte $\mathrm{K}$, et al. Cardiac dose sparing and avoidance techniques in breast cancer radiotherapy. Radiother Oncol (2014). doi:10.1016/j.radonc. 2014.04.009
18. Smith BD, Arthur DW, Buchholz TA, Haffty BG, Hahn CA, Hardenbergh PH, et al. Accelerated partial breast irradiation consensus statement from the American Society for Radiation Oncology (ASTRO). Int J Radiat Oncol Biol Phys (2009) 74(4):987-1001. doi:10.1016/j.ijrobp.2009.02.031

19. Stewart AJ, O'Farrell DA, Cormack RA, et al. Dose volume histogram analysis of normal structures associated with accelerated partial breast irradiation delivered by high dose rate brachytherapy and comparison with whole breast external beam radiotherapy fields. Radiat Oncol (2008) 3:39. doi:10.1186/1748-717X-3-39

Conflict of Interest Statement: The authors declare that the research was conducted in the absence of any commercial or financial relationships that could be construed as a potential conflict of interest.

Received: 08 August 2014; accepted: 14 September 2014; published online: 07 October 2014

Citation: Khan AJ, Goyal S and Vicini FA (2014) Cardiac avoidance in breast radiotherapy: many choices for a worthwhile objective. Front. Oncol. 4:269. doi: 10.3389/fonc.2014.00269

This article was submitted to Radiation Oncology, a section of the journal Frontiers in Oncology.

Copyright (c) 2014 Khan, Goyal and Vicini. This is an open-access article distributed under the terms of the Creative Commons Attribution License (CC BY). The use, distribution or reproduction in other forums is permitted, provided the original author(s) or licensor are credited and that the original publication in this journal is cited, in accordance with accepted academic practice. No use, distribution or reproduction is permitted which does not comply with these terms. 